\title{
VARIASI FAKTOR EKSPOSI PADA PEMERIKSAAN SCHEDEL PROYEKSI ANTERIOR POSTERIOR UNTUK HASIL RADIOGRAFI YANG MAKSIMAL DI RUMAH SAKIT AL ISLAM BANDUNG
}

\author{
Oktarina Damayanti ${ }^{1 *}$, Leny Anggraeni², Surdiyah Ningrum ${ }^{1}$ \\ ${ }^{1}$ Prodi Diploma Tiga Radiologi Politeknik Al Islam Bandung \\ ${ }^{2}$ AKTEK Radiodiagnostik dan Radioterapi Patriot Bangsa Lampung \\ Email: oktarina_st@gmail.co.id
}

\begin{abstract}
ABSTRAK
Pemeriksaan kepala merupakan pemeriksaan yang sering dilakukan di setiap rumah sakit terutama dengan menggunakan proyeksi Antero-Posterior. Kualitas hasil gambaran radiografi baik kontras, densitas, dan detailnya sangat diperlukan sehingga faktor eksposi akan sangat berpengaruh pada pemeriksaan kepala. Penelitian ini dilakukan di Rumah Sakit Al Islam Bandung dengan menggunakan phantom kepala. Pada penelitian ini jumlah $\mathrm{kV}$ dan $\mathrm{mAs}$ yang diberikan bervariasi yaitu proyeksi $A P$ dengan $64 \mathrm{kV}$ dan 11,2 mAs, schedel AP dengan $72 \mathrm{kV}$ dan 14,2 mAs, kepala $A P$ dengan $80 \mathrm{kV}$ dan 12,6 mAs, kepala $A P$ dengan $88 \mathrm{kV}$ dan 14,2 mAs, dan Radiograf kepala $A P$ dengan $96 \mathrm{kV}$ dan $16,0 \mathrm{mAs}$. Nilai faktor eksposi yang maksimal pada phantom kepala dengan proyeksi antero-posterior berdasarkan data adalah nilai responden yang mengalami perubahan dan hanya satu yang sama atau mirip dari sudut pandang responden. Penggunaan $\mathrm{kV} 64$ dan mAs 11,2 menghasilkan nilai densitas dari ke sepuluh responden sebesar 94\%, nilai kontras dari kesepuluh responden sebesar $68 \%$, nilai ketajaman dari kesepuluh responden sebesar $74 \%$, dan nilai detail dari kesepuluh responden sebesar 74\%. Pada penggunaan kV 72 dan mAs 14,2 didapat nilai densitas dari ke sepuluh responden adalah sebesar $42 \%$, nilai kontras dari kesepuluh responden sebesar $44 \%$, nilai ketajaman dari kesepuluh responden sebesar $38 \%$, dan nilai detail dari kesepuluh responden sebesar 38\%. Penggunaan $\mathrm{kV} 80$ dan mAs 12,6 menghasilkan nilai densitas dari ke sepuluh responden sebesar 56\%, nilai kontras dari kesepuluh responden sebesar $44 \%$, nilai ketajaman dari kesepuluh responden sebesar $40 \%$, dan nilai detail dari kesepuluh responden sebesar $40 \%$. Pada penggunaan $\mathrm{kV} 88$ dan mAs 14,2 memiliki nilai densitas dari ke sepuluh responden sebesar $78 \%$, nilai kontras dari kesepuluh responden sebesar 64\%, nilai ketajaman dari kesepuluh responden sebesar $64 \%$, dan nilai detail dari kesepuluh responden sebesar 64\%. Dan pada penggunaan $\mathrm{kV} 96$ dan mAs 16,0 nilai densitas, nilai kontras, nilai ketajaman, dan nilai detail dari ke sepuluh responden secara berurutan adalah sebesar $78 \%, 76 \%, 64 \%$, dan $80 \%$. Menurut penilaian kesepuluh responden yang dilakukan expose di Rumah Sakit Al Islam Bandung tersebut dapat disimpulkan bahwa hasil gambaran radiograf pertama dengan faktor eksposi $\mathrm{kV} 64$ dan mAs 11,2 memiliki nilai yang paling tinggi. Sementara nilai indeks yang paling rendah dari setiap responden dihasilkan dari variasi faktor eksposi $\mathrm{kV} 72$ dan $\mathrm{mAs}$ 14,2.
\end{abstract}

Kata Kunci: antero-posterior, kepala, kV, mAs 


\begin{abstract}
Head examination is the examination that is often performed at hospitals which mostly use Antero-Posterior projection. The quality of good radiographs that cover contrast, density and detail are needed so that the exposure factors used will be very influential on the head examination. The study was conducted at Al Islam Hospital of Bandung by using a head phantom. Variations in $k V$ and $m A s$ were given in each examination including AP projections with $64 \mathrm{kV}$ and $11.2 \mathrm{mAs}$, AP schedel with $72 \mathrm{kV}$ and 14.2 $\mathrm{mAs}$, AP head with $80 \mathrm{kV}$ and $12.6 \mathrm{mAs}$, AP head with $88 \mathrm{kV}$ and $14,2 \mathrm{mAs}$, and AP head with $96 \mathrm{kV}$ and $16.0 \mathrm{mAs}$. Based on the data, the maximum exposure factor value on the head phantom with antero-posterior projection is the respondent's value that has changed and is only one with the same or similar value from the respondent's perspective. Results of the study showed that the use of $64 \mathrm{kV}$ and $11.2 \mathrm{mAs}$ on the ten respondents produced a density value of $94 \%$, the contrast value of $68 \%$, the sharpness value of $74 \%$, and the detail value of $74 \%$. The use of $72 \mathrm{kV}$ and $14.2 \mathrm{mAs}$ the ten respondents showed the density value of $42 \%$, the contrast value of $44 \%$, the sharpness value of $38 \%$, and the detail value of $38 \%$. The use of $80 \mathrm{kV}$ and $12.6 \mathrm{mAs}$ on the ten respondents resulted the density value of 56\%, the contrast value of $44 \%$, the sharpness value of $40 \%$, and the detail value of $40 \%$. The use of $88 \mathrm{kV}$ and 14.2 $m A s$ on the ten respondents showed the density value of $78 \%$, the contrast value of $64 \%$, the sharpness value of $64 \%$, and the detail value of $64 \%$. And the last, in the use of $96 \mathrm{kV}$ and $16.0 \mathrm{mAs}$ on the ten respondents, the density value, the contrast value, the sharpness value, and the detail value of the ten respondents respectively were 78\%, 76\%,64\%, and 80\%. According to the evaluation of the ten respondents being exposed at Al Islam Hospital of Bandung, it can be concluded that the first radiograph using with the exposure factors of $64 \mathrm{kV}$ and $11.2 \mathrm{mAs}$ showed the highest value. Meanwhile, the lowest index value of each respondent was resulted from the exposure factor of $72 \mathrm{kV}$ and $14.2 \mathrm{mAs}$.
\end{abstract}

Keywords: antero-posterior, head, $k V, m A s$

\title{
PENDAHULUAN
}

Sinar $\mathrm{X}$ adalah pancaran gelombang elektromagnetik yang sejenis dengan gelombang radio, panas, cahaya, dan sinar ultraviolet tetapi dengan panjang gelombang yang sangat pendek. Sinar bersifat heterogen, panjang gelombangnya bervariasi dan tidak terlihat. Perbedaan antara sinar X dengan sinar elektromagnetik lainnya juga terletak pada panjang gelombang, di mana panjang gelombang sinar X sangat pendek yaitu 1/10000 panjang gelombang cahaya yang terlihat. Karena panjang gelombangnya yang sangat pendek maka sinar X dapat menembus benda - benda (Rasad, 2015).

Radiasi yang digunakan dalam bidang radiodiagnostik juga adalah radiasi sinar X. Karena sinar X memancarkan gelombang elektromagnetik yang memiliki panjang gelombang yang sangat pendek tersebut maka sinar $\mathrm{X}$ dapat menembus organ atau jaringan pada tubuh manusia. Sinar X dapat menembus benda, dan pada pemeriksaan radiografi sinar $\mathrm{X}$ menggunakan daya tembus yang sangat besar. Semakin tinggi tegangan pada tabung yang ditunjukkan dengan besarnya $\mathrm{kV}$ yang akan digunakan, maka semakin besar pula daya tembus sinar $\mathrm{X}$ terhadap benda.

Pada citra radiograf daya tembus diperoleh dengan cara memberikan pengaturan yang tepat pada faktor eksposi antara tegangan tabung dalam satuan $\mathrm{kV}$ (kilo Volt) arus tabung dengan satuan $\mathrm{mA}$ (miliAmper), waktu dengan satuan s, dan faktor jarak FFD (Focus Film Distance) serta luas lapangan penyinaran atau kolimasi (Rasad, 2015). 
Pada teknik pemeriksaan kepala dibutuhkan hasil radiograf yang maksimal, sehingga untuk mendapatkan hasil yang maksimal maka diperlukan faktor eksposi yang tepat. Sementara itu untuk penggunaan nilai $\mathrm{mAs}$ dari beberapa radiografer yang penulis temui pada saat pengumpulan data di lapangan, penulis melihat kebiasaan setiap radiografer yang berbeda dalam menentukan faktor eksposi pada pemeriksaan schedel dengan proyeksi Antero-Posterior.

Perbedaan pada hasil radiograf dari beberapa radiografer tersebut didasari oleh penggunaan nilai $\mathrm{kV}$ dan $\mathrm{mAs}$ yang berbeda-beda. Perbedaan dalam radiograf schedel disebabkan karena adanya perbedaan besar intensitas radiasi yang mencapai film yang dipengaruhi oleh adanya perbedaan penggunaan nilai $\mathrm{kV}$ dan $\mathrm{mAs}$ yang terjadi dilapangan pada saat pembuatan radiograf dari pemeriksaan schedel AnteroPosterior. Oleh karena itu, melalui penelitian ini penulis bermaksud untuk mencari faktor eksposi mana yang paling tepat digunakan pada pemeriksaan schedel dengan proyeksi AnteroPosterior untuk menghasilkan gambaran radiograf yang maksimal.

Berdasarkan pengamatan yang dilakukan di rumah sakit Al Islam Bandung, peneliti akan membandingan kualitas gambaran radiograf schedel dengan proyeksi Antero-Posterior yang menggunakan berbagai variasi faktor eksposi di Rumah Sakit Al Islam Bandung dan mengetahui berapa faktor eksposi yang tepat pada pemeriksaan Schedel dengan proyeksi Anterio-Posterior di Rumah Sakit Al Islam Bandung.

\section{METODOLOGI PENELITIAN}

Penelitian ini dilakukan di Instalasi Radiologi Rumah Sakit Al Islam Bandung mulai dari bulan Mei hingga September tahun 2019. Penelitian ini menggunakan metode penelitian kuantitatif dengan study eksperimen. Pengambilan sample pada pemeriksaan schedel pada proyeksi AnteroPosterior dilakukan pada phantom kepala yang berada di Rumah Sakit Al Islam Bandung.

\section{HASIL DAN PEMBAHASAN}

Hasil radiograf penelitian yang menggunakan berbagai variasi faktor eksposi dapat dilihat pada gambar di bawah ini.

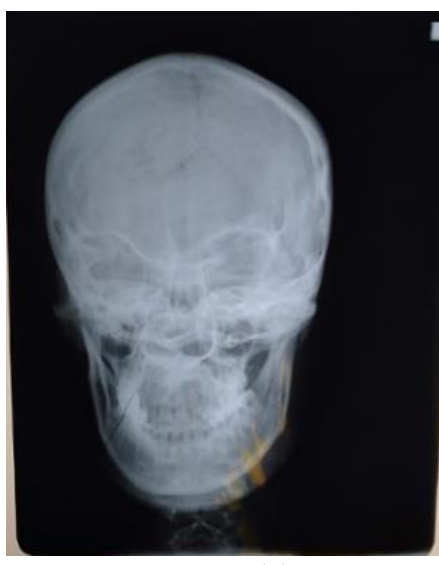

(a)

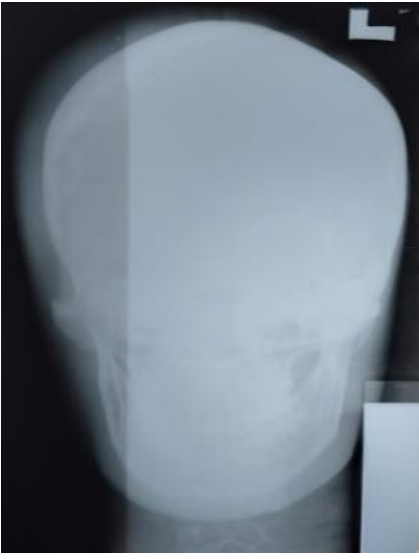

(b) 


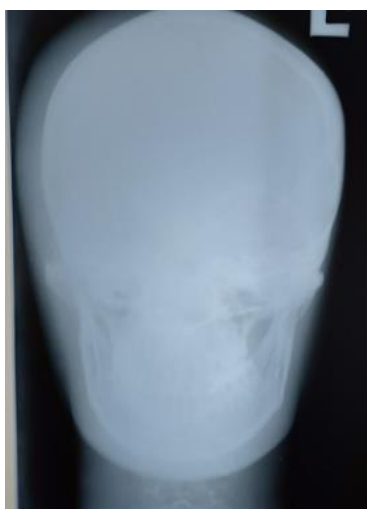

(c)

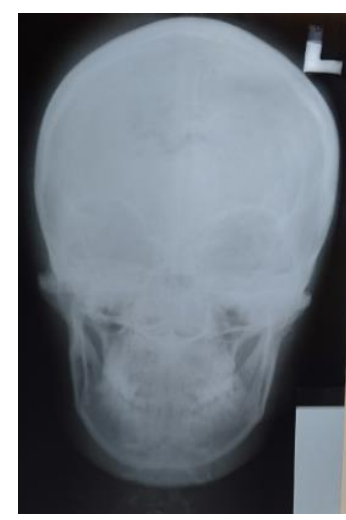

(d)

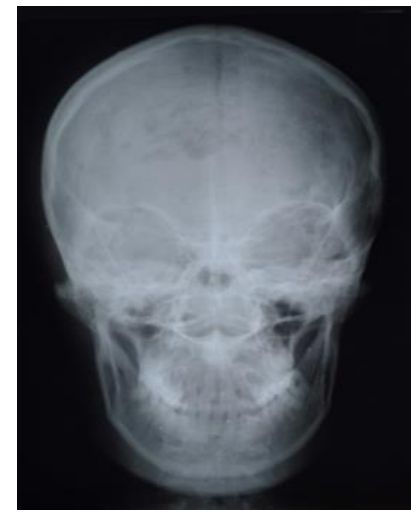

(e)

Gambar 1. Hasil radiograf schedel AP dengan (a) kV 64 dan mAs 11,2 (b) kV 72 dan mAs 14,2 (c) kV 80 dan mAs 12,6 (d) kV 88 dan mAs 14,2 (e) kV 96 dan mAs 16,0

Tabel 1. Format Angket Kuisioner Untuk Responden

\begin{tabular}{|c|c|c|c|c|c|c|c|c|c|c|c|c|c|c|c|c|c|c|c|c|c|c|}
\hline \multirow{3}{*}{$\begin{array}{c}\text { Hasil } \\
\text { Radiograf } \\
\text { Schedel }\end{array}$} & \multicolumn{2}{|c|}{ Eksposi } & \multicolumn{20}{|c|}{ Kualitas Radiograf } \\
\hline & \multirow{2}{*}{$\mathbf{k V}$} & \multirow{2}{*}{ mAs } & \multicolumn{5}{|c|}{ Densitas } & \multicolumn{5}{|c|}{ Kontras } & \multicolumn{5}{|c|}{ Ketajaman } & \multicolumn{5}{|c|}{ Detail } \\
\hline & & & 5 & 4 & 3 & 2 & 1 & 5 & 4 & 3 & 2 & 1 & 5 & 4 & 3 & 2 & 1 & 5 & 4 & 3 & 2 & 1 \\
\hline 1) & 64 & 10,2 & & & & & & & & & & & & & & & & & & & & \\
\hline 2) & 72 & 14,2 & & & & & & & & & & & & & & & & & & & & \\
\hline 3) & 80 & 12,6 & & & & & & & & & & & & & & & & & & & & \\
\hline 4) & 88 & 14,2 & & & & & & & & & & & & & & & & & & & & \\
\hline 5) & 96 & 16,0 & & & & & & & & & & & & & & & & & & & & \\
\hline
\end{tabular}

a. Kuisioner angket hasil radiograf pada pemeriksaan schedel dengan proyeksi antero-posterior. Dengan keterangan bobot nilai sebagai berikut:

Nilai 5 : Sangat Bagus (SB)

Nilai 4 : Bagus (B)

Nilai 3 : Netral / Sedang (N)

Nilai 2 : Tidak Bagus (TB)

Nilai 1 : Sangat Tidak Bagus (STB)

b. Setelah kuisioner di atas diisi oleh 10 orang responden maka perlu adanya rekap dari semua hak angket yang diberikan kepada responden. Tabel rekap kuisioner tersebut berjumlah 5 tabel disesuaikan dengan variasi faktor eksposinya.

Rumus sebagai berikut :

$$
\begin{aligned}
\mathrm{Y} & =\text { skor tertinggi (bobot nilai) } \mathrm{x} \\
& =5 \times 10=50 \\
\mathrm{X} & =\text { skor terendah (bobot nilai) } \mathrm{x} \mathrm{R} \\
& =1 \times 10=10
\end{aligned}
$$

Rumus indeks $=$ total skor $($ jumlah $) / Y$

Ket : $\mathrm{R}=$ Responden

c. Persentase nilai dan penjumlahan persentase setiap faktor eksposi dijelaskan pada Tabel 2 . sebagai berikut:

Tabel 2. Persentase Nilai dan Penjumlahan

\begin{tabular}{|c|c|}
\hline Persentase & Keterangan \\
\hline $0 \%-19.99 \%$ & Sangat Tidak Bagus \\
\hline $20 \%-39.99 \%$ & Tidak Bagus \\
\hline $40 \%-59.99 \%$ & Netral/Sedang \\
\hline $60 \%-79.99 \%$ & Bagus \\
\hline $80-100 \%$ & Sangat Bagus \\
\hline
\end{tabular}




\section{Hasil Rekap Kuisioner}

Tabel 3. Rekap kuisioner untuk faktor eksposi $64 \mathrm{kV}$ dan 11,2 mAs

\begin{tabular}{|c|c|c|c|c|c|c|c|}
\hline & SB $\times$ R & B $\times \mathbf{R}$ & N $\mathbf{~ R ~}$ & TB x R & STB x R & Jumlah & Indeks \\
\hline Densitas & $5 \times 7=35$ & $4 \times 3=12$ & $3 \times 0=0$ & $2 \times 0=0$ & $1 \times 0=0$ & 47 & $94 \%$ \\
\hline Kontras & $5 \times 0=0$ & $4 \times 7=28$ & $3 \times 1=3$ & $2 \times 1=2$ & $1 \times 1=1$ & 34 & $68 \%$ \\
\hline Ketajaman & $5 \times 0=0$ & $4 \times 9=36$ & $3 \times 0=0$ & $2 \times 0=0$ & $1 \times 1=1$ & 37 & $74 \%$ \\
\hline Detail & $5 \times 0=0$ & $4 \times 9=36$ & $3 \times 0=0$ & $2 \times 0=0$ & $1 \times 1=1$ & 37 & $74 \%$ \\
\hline
\end{tabular}

Tabel 4. Rekap Kuisioner untuk faktor eksposi $72 \mathrm{kV}$ dan 14,2 mAs

\begin{tabular}{|c|c|c|c|c|c|c|c|}
\hline & SB $\mathbf{x}$ & $\mathbf{B} \times \mathbf{R}$ & $\mathbf{N} \times \mathbf{R}$ & $\mathbf{T B} \times \mathbf{R}$ & STB $\mathbf{~ R}$ & Jumlah & Indeks \\
\hline Densitas & $5 \times 0=0$ & $4 \times 0=0$ & $3 \times 1=3$ & $2 \times 9=18$ & $1 \times 0=0$ & 21 & $42 \%$ \\
\hline Kontras & $5 \times 0=0$ & $4 \times 0=0$ & $3 \times 2=6$ & $2 \times 8=16$ & $1 \times 0=0$ & 22 & $44 \%$ \\
\hline Ketajaman & $5 \times 0=0$ & $4 \times 0=0$ & $3 \times 0=0$ & $2 \times 9=18$ & $1 \times 1=1$ & 19 & $38 \%$ \\
\hline Detail & $5 \times 0=0$ & $4 \times 0=0$ & $3 \times 0=0$ & $2 \times 9=18$ & $1 \times 1=1$ & 19 & $38 \%$ \\
\hline
\end{tabular}

Tabel 5. Rekap Kuisioner untuk faktor eksposi $80 \mathrm{kV}$ dan 12,6 mAs

\begin{tabular}{|c|c|c|c|c|c|c|c|}
\hline & SB $\times$ R & B $\times$ R & N $\times$ R & TB $\times$ R & STB x R & Jumlah & Indeks \\
\hline Densitas & $5 \times 0=0$ & $4 \times 0=0$ & $3 \times 9=27$ & $2 \times 0=0$ & $1 \times 1=1$ & 28 & $56 \%$ \\
\hline Kontras & $5 \times 0=0$ & $4 \times 0=0$ & $3 \times 3=9$ & $2 \times 6=12$ & $1 \times 1=1$ & 22 & $44 \%$ \\
\hline Ketajaman & $5 \times 0=0$ & $4 \times 0=0$ & $3 \times 1=3$ & $2 \times 8=16$ & $1 \times 1=1$ & 20 & $40 \%$ \\
\hline Detail & $5 \times 0=0$ & $4 \times 0=0$ & $3 \times 1=3$ & $2 \times 8=16$ & $1 \times 1=1$ & 20 & $40 \%$ \\
\hline
\end{tabular}

Tabel 6. Rekap Kuisioner untuk faktor eksposi $88 \mathrm{kV}$ dan 14,2 mAs

\begin{tabular}{|c|c|c|c|c|c|c|c|}
\hline & SB $\times$ R & $\mathbf{B} \times \mathbf{R}$ & $\mathbf{N} \times \mathbf{R}$ & $\mathbf{T B} \times \mathbf{R}$ & STB $\times \mathbf{R}$ & Jumlah & Indeks \\
\hline Densitas & $5 \times 0=0$ & $4 \times 9=36$ & $3 \times 1=3$ & $2 \times 0=0$ & $1 \times 0=0$ & 39 & $78 \%$ \\
\hline Kontras & $5 \times 0=0$ & $4 \times 2=8$ & $3 \times 8=24$ & $2 \times 0=0$ & $1 \times 0=0$ & 32 & $64 \%$ \\
\hline Ketajaman & $5 \times 0=0$ & $4 \times 2=8$ & $3 \times 8=24$ & $2 \times 0=0$ & $1 \times 0=0$ & 32 & $64 \%$ \\
\hline Detail & $5 \times 0=0$ & $4 \times 2=8$ & $3 \times 8=24$ & $2 \times 0=0$ & $1 \times 0=0$ & 32 & $64 \%$ \\
\hline
\end{tabular}

Tabel 7. Rekap Kuisioner untuk faktor eksposi $96 \mathrm{kV}$ dan 16,0 mAs

\begin{tabular}{|c|c|c|c|c|c|c|c|}
\hline & SB $\mathbf{~ R}$ & $\mathbf{B} \times \mathbf{R}$ & $\mathbf{N} \times \mathbf{R}$ & TB $\mathbf{R}$ & STB $\mathbf{R}$ & Jumlah & Indeks \\
\hline Densitas & $5 \times 1=5$ & $4 \times 7=28$ & $3 \times 2=6$ & $2 \times 0=0$ & $1 \times 0=0$ & 39 & $78 \%$ \\
\hline Kontras & $5 \times 1=5$ & $4 \times 7=28$ & $3 \times 1=3$ & $2 \times 1=2$ & $1 \times 0=0$ & 38 & $76 \%$ \\
\hline Ketajaman & $5 \times 1=5$ & $4 \times 0=0$ & $3 \times 9=27$ & $2 \times 0=0$ & $1 \times 0=0$ & 32 & $64 \%$ \\
\hline Detail & $5 \times 1=5$ & $4 \times 8=32$ & $3 \times 1=3$ & $2 \times 0=0$ & $1 \times 0=0$ & 40 & $80 \%$ \\
\hline
\end{tabular}

\section{Penjumlahan Indeks Tiap Film}

a. Maka, jumlah indeks faktor eksposi $64 \mathrm{kV}$ dan 11,2 mAs yaitu 310\% / $4=77,5 \%$

b. Maka, jumlah indeks faktor eksposi $72 \mathrm{kV}$ dan $14,2 \mathrm{mAs}$ yaitu $162 \% / 4=40,5 \%$

c. Maka, jumlah indeks faktor eksposi $80 \mathrm{kV}$ dan $12,6 \mathrm{mAs}$ yaitu $180 \% / 4=45 \%$

d. Maka, jumlah indeks faktor eksposi $88 \mathrm{kV}$ dan $14,2 \mathrm{mAs}$ yaitu $270 \% / 4=67,5 \%$

e. Maka, jumlah indeks faktor eksposi $96 \mathrm{kV}$ dan 16,0 mAs yaitu $298 \% / 4=74,5 \%$ 


\section{Hasil Indeks Dengan Diagram}

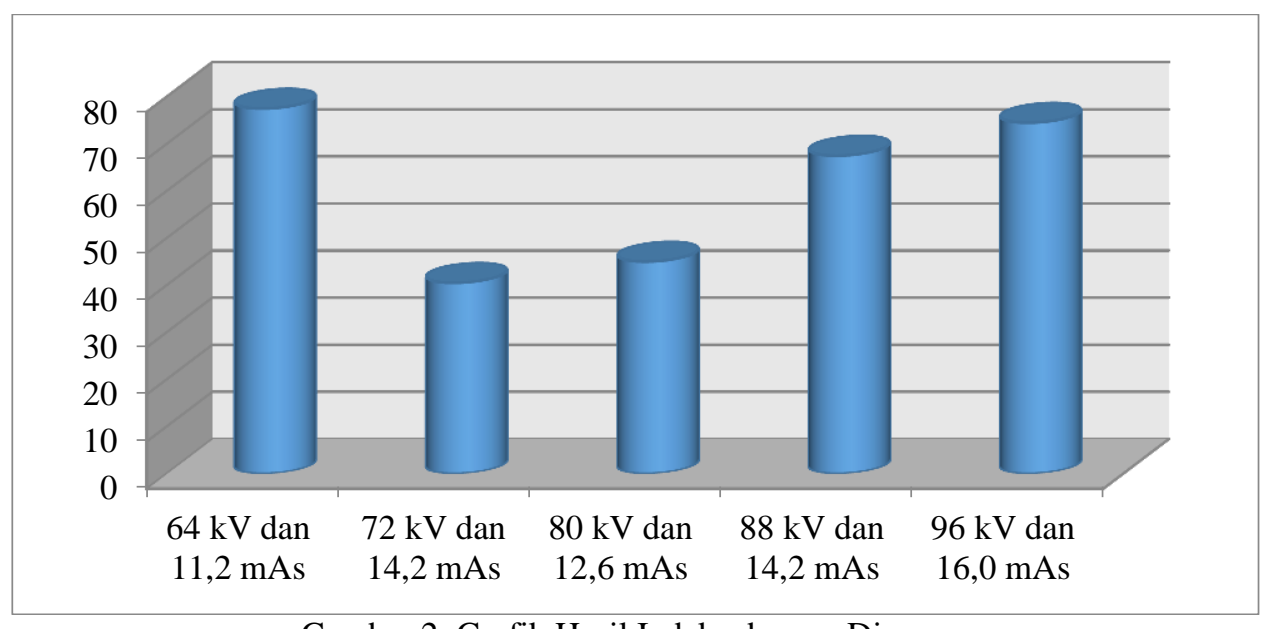

Gambar 2. Grafik Hasil Indeks dengan Diagram

\section{KESIMPULAN}

Nilai faktor eksposi yang maksimal pada phantom kepala dengan proyeksi antero-posterior berdasarkan data tabel yang telah dijelaskan di atas menunjukkan nilai responden mengalami perubahan dan hanya satu yang sama atau mirip dari sudut pandang responden.

Pada penggunaan variasi $\mathrm{kV} 64$ dan $\mathrm{mAs} 11,2$ dari sepuluh responden tersebut didapat nilai densitas sebesar $94 \%$, nilai kontras sebesar $68 \%$, nilai ketajaman sebesar $74 \%$, dan nilai detail sebesar $74 \%$. Sementara pada penggunaan variasi $\mathrm{kV} 72$ dan $\mathrm{mAs} 14,2$ nilai densitas, nilai kontras, nilai ketajaman, dan nilai detail yang diberikan oleh sepuluh responden tersebut adalah secara berturut-turut sebesar $42 \%, 44 \%, 38 \%$, dan $38 \%$.

Pada penggunaan $\mathrm{kV} 80$ dan $\mathrm{mAs}$ 12,6 sepuluh responden di atas memberikan nilai densitas $56 \%$, nilai kontras sebesar $44 \%$, nilai ketajaman sebesar $40 \%$, dan nilai detail sebesar $40 \%$.

Pada penggunaan variasi $\mathrm{kV} 88$ dan mAs 14,2 persentase yang didapat dari sepuluh responden di atas sebesar $78 \%$ untuk nilai densitas, $64 \%$ untuk nilai kontras, $64 \%$ untuk nilai ketajaman, dan $64 \%$ untuk nilai detail. Dan yang terakhir pada penggunaan variasi kV 96 dan mAs 16,0 nilai densitas, nilai kontras, nilai ketajaman, dan nilai detail dari ke sepuluh responden adalah sebesar $78 \%, 76 \%, 64 \%$, dan $80 \%$.

Menurut penilaian dari sepuluh responden itu dapat disimpulkan bahwa setelah dilakukan expose di Rumah Sakit Al Islam Bandung, hasil radiograf pertama dengan faktor eksposi kV 64 dan mAs 11,2 memiliki nilai yang paling tinggi. Sementara itu nilai indeks yang paling rendah yang didapat dari setiap responden diberikan pada gambaran radiograf yang menggunakan variasi faktor eksposi $\mathrm{kV} 72$ dan mAs 14,2. 


\section{DAFTAR PUSTAKA}

Ball, John and Price, Tony. (1990). Chesney's Radiogrhapic Imaging (5th ed). Oxford, London : Blackwell Scientific Publications.

Balinger, W. Philip and Frank, D. Eugene. (2010). Merrill's Atlas Of Radiogrhapic Positions and Radiologic Procedures (10th ed Vol 2). Missouri, USA :Mosby.

Berkala Fisika, Vol 1. No 2. (2008). Hal 45 - 52. Variassi Nilai Eksposi Aturan 15 Persen pada Radiograph. (http://eprints.undip.ac.id)

Bontrager, L. Kenneth and Lampignano, P. John. (2014). Text Of Radiographic Positioning And Related Anatomy (8th ed). USA : Elsevier Mosby.

Bushong, C. Stewart. (2013). Radiologic Science For Technologist (10th ed). Houtson, Texas : Elsevier Mosby.

Ekayuda, Iwan. (2005) Radiologi Diagnostik (2nd ed). Jakarta : Badan Penerbit FKUI.

Pearce, E. C. (2011). Anatomi dan Fisiologi Untuk Paramedis. (Cet. 35). Jakarta : Gramedia Pustaka Utama.

Perka Badan Pengawas Tenaga Nuklir (BAPETEN) No 4 Tahun 2013 Tentang Proteksi Dan Keselamatan Radiasi Dalam Pemanfaatan Tenaga Nuklir.

Whitney, A. Stewart etc. (2005). Clark's Positioning In Radiography (12th ed). London : A Member Of The Hodder Headline Group 